\title{
Un "coyote" japonés en Ciudad Juárez (1905-1911)
}

JORGE DURAND

\author{
Introducción
}

A Japanese Coyote in Ciudad

Juárez (1905-1911)

JORGE DURAND

Universidad de GuadalajaraCentro de Investigación y Docencia Económicas, Distrito Federal, México j.durand.mmp@gmail.com

Traducción: Marisa Raditsch

Desacatos 46, septiembre-diciembre 2014, pp. 192-207 as buenas bibliotecas siempre contienen gratas sorpresas. Tratarlas con deferencia, conocerlas poco a poco y perder el tiempo en ellas siempre da frutos. Un ejemplo son estas cartas, comunicaciones y reportes del Immigration and Naturalization Services (INS) sobre el cruce subrepticio de chinos y japoneses a comienzos del siglo xx por la frontera de México y Estados Unidos, entre Ciudad Juárez y El Paso. Durante una estancia de investigación y docencia en la Universidad de Chicago solía quedarme en la biblioteca y esperar el último autobús que salía del campus, a las 12 de la noche, para repartir estudiantes que se habían quedado a trabajar hasta tarde, algunos incluso se quedaban a dormir allí en cómodos sillones. Así descubrí la sección de microfilmes y entré a curiosear en los archivos hasta dar con un lote de rollos del INS. Los textos recogidos aquí son una selección de documentos que hablan del cruce fronterizo. El primero es del 3 de enero de 1905 y el último del 7 de octubre de 1911. Se encuentran en la sección de microfilmes de la Biblioteca Rigenstein (Series A Microfilm, JV6455.684, 1994, V2). La traducción del inglés al español estuvo a cargo de Marisa Raditsch y la corrección estilo fue realizada por Celeste González.

El contexto y la época se refieren a la Ley de Exclusión de Chinos (1882) y al acuerdo migratorio con Japón, conocido como el Gentlemen's Agreement ("Pacto de caballeros") (1907), que limitaban la entrada de inmigrantes de Oriente y que causaron, por una parte, el asentamiento de migrantes en la región fronteriza y, por otra, el tráfico subrepticio. La migración japonesa a México tiene su punto de partida en 1888 con el Tratado de Amistad, Comercio y Navegación entre los dos países, pero es hasta 1897 en que llega el primer grupo de colonos al Soconusco, en Chiapas (Ota, 1985). Después llegaría la segunda de 
siete oleadas, a la que Ota califica como la de los "braceros", trabajadores migrantes que llegaban en su mayoría a Manzanillo y luego se dispersaban para trabajar en la construcción de vías férreas, en las haciendas cañeras y en las minas, con la salvedad de que la mayoría de estos supuestos braceros tarde o temprano “cruzó hacia Estados Unidos” (Ota, 1985: 56).

La mayoría de los inmigrantes japoneses eran hombres - 76\% - y muchos provenían de las provincias de Okinawa, de la isla de Honshu, o de la prefectura de Fukuoka. Dada la alta tasa de masculinidad, algunos optaron por casarse con mexicanas para asentarse de manera definitiva en el país y obtener la nacionalidad. Ya con los documentos en regla podían traer a otros parientes. A pesar del Pacto de Caballeros de 1907, en el que Japón se compromete a no enviar más inmigrantes a Estados Unidos, muchos de los que llegaron a México en esa época, fueran braceros o inmigrantes "ilegales" (sic) (Ota, 1985), tenían la intención final de cruzar a Estados Unidos. Para ello contaban con el apoyo de una colonia japonesa establecida en Ciudad Juárez dedicada al comercio de abarrotes citadino y con un buen servicio de coyotaje que, según los documentos, tenía conocimiento y experiencia amplios en el trasiego fronterizo y buenos contactos con autoridades estadounidenses.

Estas cartas y reportes administrativos ponen al descubierto una serie de temas, problemas y prácticas tan añejos como contemporáneos. Uno de ellos tiene que ver con las tensiones y el reparto de responsabilidades entre funcionarios, como suele ser natural en asuntos migratorios en los que intervienen varias dependencias. Por ejemplo, el Departamento de Trabajo y Comercio recrimina en un oficio a los funcionaros del INS porque no todos se dedican a aplicar la Ley de Exclusión de Chinos, lo que recuerda las tensiones actuales entre los gobiernos estatales y el federal en aspectos migratorios. Otro tema recurrente en los documentos es la corrupción de los funcionarios en la zona fronteriza, manifiesta en múltiples casos. El de los traductores oficiales de japonés es reseñado en los documentos que se transcriben. En otros casos se habla del personal de la patrulla fronteriza, que deja el paso libre para ingresar a Estados Unidos, incluso a aquellos inmigrantes enfermos de tracoma, un problema crítico en aquellos tiempos.

Por otra parte, se aprecia con claridad, en varias entrevistas e informes oficiales, la manera de operar de los “coyotes” japoneses en Ciudad Juárez a comienzos del siglo xx. Recibían a los inmigrantes en la estación de tren, luego les daban "refugio" en casas u hoteles, donde los custodiaban hasta que las agencias especializadas se encargaran, previo pago, del cruce fronterizo. Se les cobraba una cuota de acuerdo con el tipo de servicio que requerían. Sin embargo, los parientes o los amigos en Estados Unidos debían pagar la cuota al "coyote" y para eso se valían de los servicios bancarios y de los giros telegráficos en Ciudad Juárez. En algunos casos los migrantes pasaban como comerciantes, para lo cual vestían adecuadamente; en otros, como el de los inmigrantes chinos, les cortaban el cabello como japoneses porque las leyes discriminatorias eran más severas para aquéllos. Hoy en día el proceso de transformación de los migrantes que quieren pasar la frontera sigue el mismo patrón o proceso de mimetización por medio de la ropa y el corte de cabello, de modo que se asemejen en apariencia a los mexicanos que ya viven en el "otro lado".

De manera similar a lo que sucede hoy en día, los migrantes de antaño tenían instrucciones precisas para el camino, en este caso para ir de Ciudad Juárez a Tucson: un camino largo, larguísimo, sobre todo si se hacía a pie. Se les indicaba seguir las rutas marcadas por los postes de telégrafo y las vías del ferrocarril, y evitar las aduanas donde había inspectores. En la actualidad, los migrantes suelen seguir el camino de las torres de electricidad que indefectiblemente llegan a poblaciones urbanas. 
La frontera siempre ha sido un lugar de tránsito, trasiego, tráfico y contrabando, pero las leyes, las restricciones y las prácticas de cada país afectan al otro. En este caso las colonias de inmigrantes chinos y japoneses que hoy se extienden en la frontera, en especial en Tijuana y Mexicali, son el resultado de la prohibición y las limitaciones a la inmigración impuestas por Estados Unidos. Muchos de estos inmigrantes no querían quedarse en México y se vieron obligados a hacerlo. Se cuenta que durante la "expedición punitiva", después de la incursión de Villa en Columbus (1916), muchos inmigrantes chinos se ofrecieron como personal de servicio del ejército estadounidense, sobre todo como cocineros. Al regresar el general Pershing, los protegió y los consideró aliados, pero eso no fue suficiente para poder cruzar la frontera libremente y resolver sus problemas.

Otro conjunto de documentos - que no se presentan en esta ocasión - se refiere a un "coyote" chino que operaba en Ciudad Juárez en 1905 y utilizaba métodos similares. Cabe hacer notar que en esos tiempos la frontera estaba prácticamente abierta. Los Texas rangers se encargaban de controlar a los "bandidos" mexicanos y al abigeato, y sólo había un control oficial en las aduanas o cruces fronterizos. La patrulla fronteriza se constituye propiamente hasta 1924.

\section{Documento 1}

Deber de los empleados del servicio de inmigración de aplicar las leyes de inmigración y de la exclusión china

Departamento de Comercio y Trabajo

Agencia de Inmigración

Washington

Circular de agencia número 10

3 de enero de 1905
Para comisionados de inmigración, inspectores de los inmigrantes chinos encargados y otros empleados del Servicio de Inmigración:

Últimamente ha llamado la atención que los empleados del Servicio de Inmigración piensan que por ser nombrados y jurar hacer cumplir las leyes de inmigración o de exclusión china, según sea el caso, su deber consiste sólo en esforzarse para hacer cumplir este conjunto de leyes que se indican en sus nombramientos y descuidan otras leyes.

Esta circular se emite para aclarar a todos los empleados del Servicio de Inmigración que están obligados tanto a hacer cumplir las leyes de inmigración como de exclusión china. Debido a que el pago de gastos y salario se hace por separado, hay una distinción entre los oficiales nombrados en las dos ramas del Servicio. Todos los empleados, si son pagados de los fondos de inmigrantes o de la asignación para la aplicación de las leyes de exclusión china, han sido ocupados y designados para ayudar a llevar a cabo los deberes generales que recaen sobre esta Agencia.

Es preferible que exista armonía entre los dos tipos de empleados, ya que la falta de comprensión y cooperación puede restar méritos a los resultados de su trabajo; los oficiales deben esforzarse para ayudar de todas las maneras posibles a aplicar de manera inteligente, eficiente e imparcial todas las leyes de las que la Agencia de Investigación se hace cargo.

F. P. Sargent, Comisionado-General

Aprobado: V. H. Metcalf, secretaria

\section{Documento 2}

Oficio sobre impedir el ingreso a enfermos de tracoma

Departamento de Comercio y Trabajo

Oficina de Inmigración y Naturalización

Washington

Número 51,463/B 
26 de enero de 1907

Señor:

Tengo el honor de confirmar la recepción de su carta de la $23^{\circ}$ instancia, archivo número 223/8-9. Las negociaciones tienen como objetivo detener la inmigración de extranjeros europeos o asiáticos con enfermedades a través del territorio mexicano.

De conformidad con la sugerencia del ministro Thompson, se hará un esfuerzo para obtener del director general de Salud del Hospital de Servicio de Salud Pública una monografía que muestre el carácter y los efectos de la enfermedad conocida como tracoma, misma que muchos extranjeros europeos y asiáticos que aterrizan en México padecen. Al recibir la información deseada, será remitida una copia al Embajador, para que las autoridades sanitarias de México tomen medidas al respecto.

Tengo el honor de ser, Señor, su sirviente obediente, (firmado) Oscar S. Strauss

Secretaría

Hon. Elihu Root,

Secretaria del Estado

\section{Documento 3}

Queja de un inmigrante japonés sobre abusos en el tráfico por la frontera

El Paso, 9 de septiembre de 1907

\section{Señor ministro:}

Supongo que la cuestión de que los inmigrantes contratados y llevados a México por la Transoceanic Immigration Company son maltratados ya ha llegado a sus oídos. Sufren de maltrato tanto en las granjas como en los ferrocarriles donde trabajan. La compañía ve por sus propios intereses y aparenta otras cosas con las palabras "benevolencia a nuestros compatriotas". Además de lo anterior, uno de los miembros de la compañía, llamado Yoshisada Nonami, que actualmente vive en la frontera mexicana, con un japonés llamado Genji Hasegawa, de esta ciudad, tortura a los inmigrantes japoneses que son detenidos en la frontera.

El señor Nonami llegó a Ciudad Juárez hace tiempo, se ganó la confianza de los inmigrantes al declarar que era un enviado para establecer una casa caritativa de alojamiento para los inmigrantes en la miseria. Esta afirmación causó que quienes estaban en la frontera confiaran en él.

A los pocos días abrió una pequeña casa, con un letrero en el cual se leía "Anglo-Japanese Society”, donde Nonami estableció su oficina. Al mismo tiempo, él estaba en contacto con la Sección de Inmigración del gobierno estadounidense, $\mathrm{cu}-$ yos agentes se dice que fueron sobornados; cuando descubrieron que algunos japoneses recibían dinero de sus parientes o amigos en Estados Unidos, Nonami hacía arreglos con los oficiales estadounidenses en la frontera para que les permitieran cruzar sin problemas con una cuota de $\$ 75.00$ a $\$ 100.00$ per cápita.

También manda cartas o agentes a varios lugares del estado de Chihuahua, donde muchos japoneses trabajan, con el engaño de que puede ayudarles a entrar a Estados Unidos. Entonces los hombres vienen hasta Ciudad Juárez, se alojan en la casa, un cuarto de la clase más baja, sin piso ni cama, les cobra diez centavos cada noche y les trata como animales. Los gastos de alimentación los pagan los mismos inmigrantes. Mientras están ahí, Nonami les sugiere que escriban a sus amigos en Estados Unidos para pedirles dinero y que esperen respuesta. Si los hombres reciben algo, les cobra una cuota de $\$ 70.00$ hasta $\$ 100.00$ para dejarlos entrar a Estados Unidos. Cuando no pueden asegurar los fondos necesarios, los corre de su casa aunque no tengan ni un centavo para vivir. Éstos son los japoneses que actualmente están en la frontera de México en pobreza absoluta. 


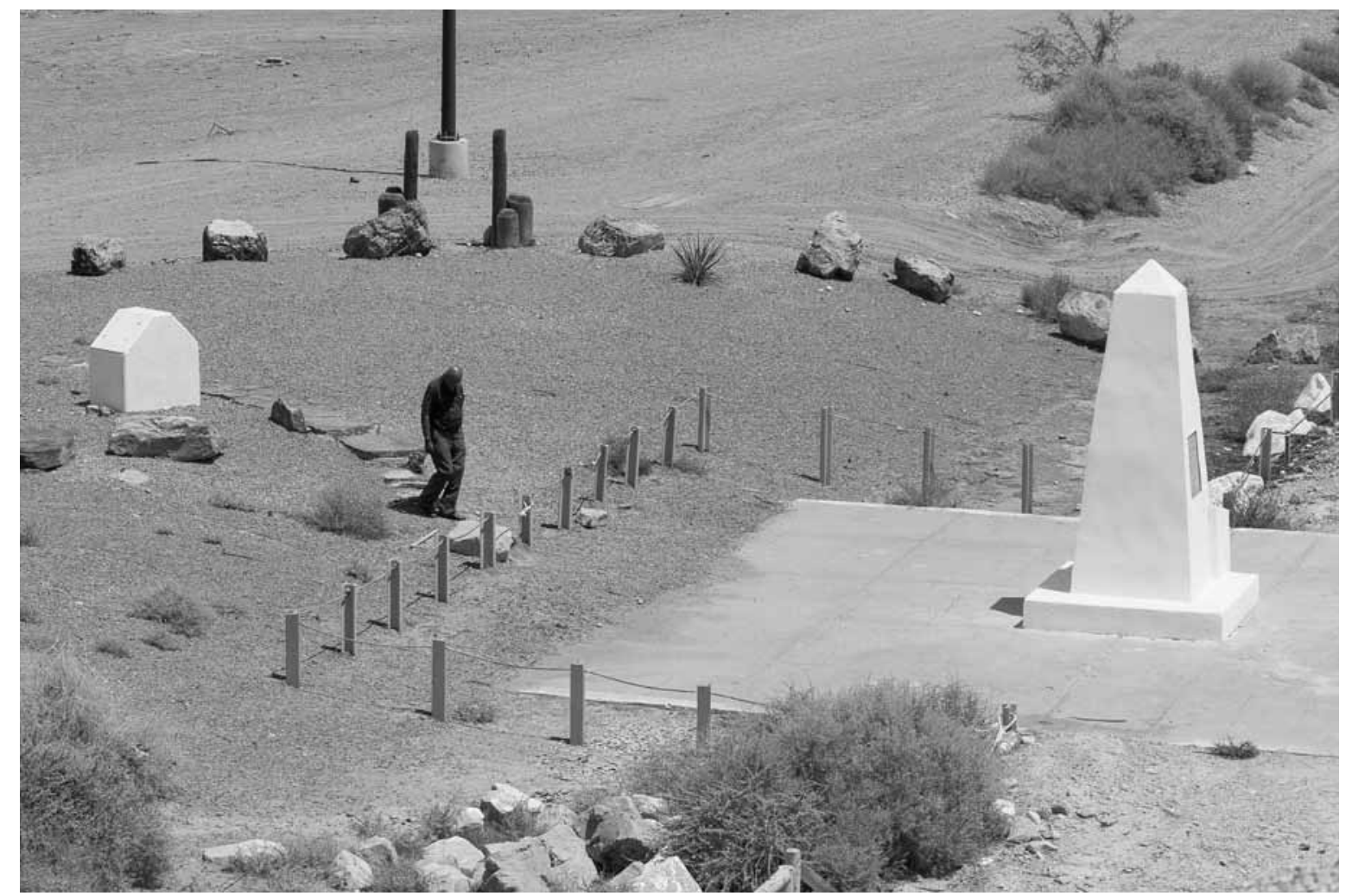

Prometeo Lucero • Frontera Ciudad Juárez-El Paso.

También tiene un registro de los inmigrantes japoneses que intentan entrar a Estados Unidos, aunque puede ser que algunos vayan a Canadá, generalmente la cuota es de $\$ 10.00$ oro o más, registra sus nombres y direcciones en un libro, en su oficina, así como en la Sección de Inmigración, el consulado o alguna oficina pública de Estados Unidos.

Dicen que Nonami tiene un nuevo socio que dirige una casa de huéspedes en El Paso para evitar que las mujeres entren con sus esposos para acompañarlos cuando no tengan los fondos necesarios para pagar la entrada a Estados Unidos y los gastos de registro o el alojamiento.

Hay un japonés que vive aquí, llamado Matsunaga, que alguna vez tuvo el cargo de intérprete de la Sección de Inmigración de Estados Unidos, un hombre bueno y honesto, que desde el momento en que supo de las malas acciones de Nonami decidió ayudar a los inmigrantes y puso una casa para alojarlos con una cuota moderada por sus servicios.

Nonami va todos los días a la estación cuando llega el tren para encontrarse con los inmigrantes, pero como Matsunaga también va al mismo lugar han tenido problemas graves con frecuencia.

Entonces Nonami ha estado en contra de la casa de alojamiento de Matsunaga y con la ayuda de los agentes estadounidenses Matsunaga fue obligado a cerrar su casa por falta de fondos. Como se mencionó anteriormente, Matsunaga es un hombre bueno y honesto, y puede actuar como testigo de las irregularidades referidas.

Todos nuestros paisanos que saben lo que ha hecho Nonami se quejan al respecto, pero como actúa con los oficiales estadounidenses no podemos 
hacer llegar nuestras quejas a las autoridades correspondientes en El Paso o Juárez. Algunos de nosotros ya nos hemos dirigido a autoridades de nuestro país por medio de una carta firmada por más de 50 personas de esta localidad.

Expongo los hechos mencionados para dar a conocer las condiciones lamentables en las que viven los inmigrantes y que son causadas por Nonami cuando los anima a cruzar la frontera. Confío en que usted se encargará de investigar los hechos y nos ayudará a liberarnos de esta difícil situación.

\section{Un inmigrante japonés}

NOTA: traducción de la carta enviada al escritor señor Rychei Otsuka, quien estaba viviendo por un tiempo en El Paso y ahora está en este país.

\section{Documento 4}

Informe sobre traficantes fronterizos en Ciudad Juárez

\section{Estimado señor:}

Debo reportarle el contrabando de los inmigrantes japoneses hacia Estados Unidos y pido su ayuda para liberarlos de los responsables.

A continuación contaré lo que sucede detrás del letrero de la Agencia Japonesa, colgado en la calle principal de Ciudad Juárez. A finales de mayo pasado un japonés llamado Genji Hasegawa se apropió de un hotel japonés, antes mantenido por otro japonés, el señor Kan. En este lugar se ha tratado de mala manera a los hombres ignorantes del campo que vienen de diferentes partes de México, tomando ventaja de sus deseos de entrar a los Estados Unidos. Cuando él conoció a Yoshisada Nonami, miembro de la Compañía Transoceánica de Emigración, a mediados de junio, planeó monopolizar el negocio para la entrada a Estados Unidos de los inmigrantes japoneses que viven en México sin importar las regulaciones que prohíben la entrada de trabajadores japoneses y coreanos al territorio de Estados Unidos, por lo que se ha violado la ley.

En un principio se corrompió a los oficiales de Inmigración y más adelante intentaron ganarse la confianza de la policía, el banco y otras oficinas que tienen relación con los inmigrantes japoneses, así que el señor Nonami es llamado el cónsul japonés incluso por la gente de los pueblos de la frontera.

El banco y la oficina de correos en Ciudad Juárez lo confundieron con un cónsul y dejaron de pagar el dinero enviado a los inmigrantes japoneses por parte de sus amigos o parientes desde varias partes de Estados Unidos, a excepción de los enviados por medio de la Agencia Japonesa. Una vez que los inmigrantes reciben dinero dependen de la Agencia. Si quieren cruzar la frontera, deben pagar una cuota de $\$ 20.00$ cuando desean ir a Canadá por la ruta señalada por la Agencia, pero si eligen la línea deben pagar $\$ 60.00$, si desean pasar como comerciantes $\$ 120.00$ y los que tengan enfermedad de la vista pueden entrar sin examen si pagan $\$ 120.00$ al señor Nonami. Es evidente a dónde va todo el dinero si se observan las relaciones entre Nonami, Hasegawa y los oficiales de Inmigración. ¡Se divide entre ellos!

Hay algunos japoneses indignados por este asunto, pero no tienen el poder para hacer algo al respecto.

Espero se haga una investigación del asunto y se salve a los inmigrantes de sus manos.

\section{Atentamente,}

Rychei Otsuka

4 de octubre de 1907.

\section{Documento 5}

Traducción de la carta de un japonés en Denver, Colorado, en la que informa sobre el tráfico fronterizo en Ciudad Juárez 
14 de octubre de 1907

Estimado señor:

Le agradezco la amabilidad que me mostró durante mi estancia en México. Crucé la frontera como un comerciante y ahora vivo en el lugar mencionado en la parte anterior.

En la frontera está el señor Nonami de la Compañía Transoceánica de Emigración (vive en El Paso actualmente), quien conspira con un hombre llamado Genji Hasegawa y por medio de los oficiales de Inmigración permite a los japoneses entrar al país, siempre y cuando le paguen una cuota de $\$ 50.00$, la que me cobraron cuando pasé por ahí, pero de acuerdo con la información de mis amigos ahora en la frontera esta cuota ha aumentado a $\$ 70.00 \mathrm{y}$ $\$ 80.00$ per cápita. Incluso para obtener el permiso para ir a Canadá cobra $\$ 10.00$.

(El Paso, Tex., 26 de diciembre de 1907)

\section{Documento 6}

Traducción de una carta escrita por Lee Wo Un, detenido en la cárcel en Alamogordo, Nuevo México, bajo acusación de estar en Estados Unidos de manera ilegal (traducción de Wong Aloy, intérprete chino).

\section{Dirigida a}

Wong Aloy:

Mi nombre es Lee Wo Un. Yo tenía un restaurante en Chicago con el nombre de Yet Lay Kew. Estoy en la cárcel, si me sacaras te pagaría 300 o 400 dólares. Mi amigo, How Yick te entregará el dinero. Tú y yo éramos buenos amigos en Chicago. How Yick ahora está en un pueblo cerca de Filadelfia, donde tiene una lavandería. Yo estaba registrado en Chicago y mi testigo se llama Lee Hong Gip. Mi número de certificado era seis mil algo. Hace un tiempo atrás deposité mi certificado con la empresa Mow Fang
Co. de San Francisco, pero fue destruido por el incendio durante el terremoto. Apreciaría mucho tu ayuda para salir de este problema. Telégrafo a How Yick de Filadelfia para entregar a la empresa de Yee Woh, núm. 915 Ray St.

\section{Documento 7}

Reporte de una conversación escuchada por un traductor japonés que trabaja con el Immigration and Naturalization Services.

Servicio de Inmigración

Oficina de inspector encargado

Laredo, Texas

3 de enero de 1908

Charles L. Babcock, Inspector de Inmigración San Antonio, Texas Señor:

La siguiente es una conversación que escuché por casualidad en Ciudad Juárez, México, durante mi reciente viaje a El Paso, Texas. La conversación se llevó a cabo entre dos japoneses, Ging Hasegawa y Tanaka, alias Kawamoto, su socio en la Agencia Japonesa.

Hasegawa: Los dos individuos que quieren entrar a Estados Unidos tienen sólo $\$ 65.00$ cada uno así que les dije que les ayudaríamos por esa cantidad en lugar de la cuota regular de $\$ 75.00$. Les dije que las cosas se van a arreglar tan pronto como sea posible, pero por supuesto tendremos que esperar porque el americano no está disponible.

TANAKa: Eso es una lástima. Quisiera que pudiéramos seguir. No me gusta la demora.

Hasegawa: No se puede evitar.

TANaka: Eso es cierto. ¿Cómo los vas a pasar?

Hasegawa: No te preocupes por eso. He arreglado bien las cosas. Van a decir que son comerciantes y 
que perdieron sus pasaportes. Seguramente van a pasar. Tendremos que esperar hasta que ese grupo vuelva a ponerse a trabajar.

TANAKA: ¿Cuándo crees que sea?

Hasegawa: No lo sé. No hay de qué preocuparse, él es bueno. Lo garantizo.

TANAKa: No me siento muy bien acerca de esta cuestión. ¿Estás seguro de que puedes confiar en el hombre?

Hasegawa: Si, él es bueno. Vamos a mandar a uno como prueba para ver si la nueva administración tendrá efecto sobre nuestros hombres.

TANAKA: ¿Y el negocio chino que habías mencionado? Hasegawa: Ese negocio todavía no está listo. Hay 15 chinos y obtendríamos $\$ 9000.00$ yen $\$ 4500.00$ oro) para pasarlos. Mi plan es hacer que se corten el cabello como los japoneses y mandarlos como si fueran japoneses.

TANAKA: Hay mucho dinero detrás de ese negocio.

Lo anterior es todo lo que pude escuchar de la conversación. También escuché otra conversación en la cual los dos hombres discutieron la necesidad de rentar otra casa para acomodar a los japoneses que esperaban en Juárez en los próximos días.

Respetuosamente,

Alfred J. White

Interprete de japonés

\section{Documento 8}

Traducción de una carta circular que describe la ruta oriental tomada por los chinos después de obtener la entrada subrepticia a Estados Unidos en El Paso.

Instrucciones de la ruta oriental a pie entre El Paso y Tucson

Del lado occidental cruza el río, ve las ciudades del oriente. Primero vas a ver muchos árboles, después el ferrocarril, pronto llegarás al segundo ferrocarril, junto a la montaña. Camina como 19 millas hasta llegar a tres o cuatro casas, la primera es donde vive la gente blanca; la segunda es donde hay un tanque, ahí puedes conseguir agua. Sigue caminando por el mismo ferrocarril, camina como 20 millas (acumulativas), y llegarás a un gran molino, también una granja de ganado. Continúa como 32 o 33 millas (acumulativas). Hay tres casas, la de en medio es donde vive la gente blanca y enfrente de esta casa hay un pozo donde puedes comprar comida y conseguir agua. Camina como 48 millas (acumulativas) y llegarás a un pequeño pueblo. Cruza por la izquierda, cerca del centro. Al lado derecho del ferrocarril hay una estación donde puedes conseguir comida y agua. Cuando salgas de ahí, camina por el ferrocarril, como 56 millas (acumulativas), hasta llegar a tres casas mexicanas y después, como a 75 millas (acumulativas), hay dos o tres casas. Ten cuidado ahí. Camina como 80 millas (acumulativas). Hay dos molinos y una casa grande. Camina 86 millas (acumulativas) y llegarás a Alamogordo.

Traducido por Wong Aloy (al inglés).

5 de enero de 1908

\section{Documento 9}

Oficio en el que se informa sobre las investigaciones y medidas para investigar y solucionar el problema del tráfico de japoneses en Ciudad Juárez

Núm. 1090 Embajada Estadounidense

México, 2 de junio de 1908

Para el Honorable

El Secretaria del Estado

Washington, D. C.

Señor:

Por este medio acuso de recibo el número 499 del Departamento del pasado 18 de mayo, sobre la 
inmigración ilegal de japoneses hacia Estados Unidos — que se ha promovido por organizaciones japonesas en Juárez-y a la cual se desea poner fin. Anexo mi telegrama de hoy, el siguiente:

Envío número cuatro noventa y nueve. El encargado de Negocios japoneses hasta ahora no tiene instrucciones oficiales y pide que no se haga nada que empeore la situación, esto pone en peligro las posibilidades de obtener información cuando él está autorizado a actuar. Enviar esta noche.

En una conferencia, el encargado de Negocios japonés, el señor Yoshida, aseguró que aunque él ha recibido copias de la correspondencia con el Departamento del Estado del embajador japonés en Washington acerca de este tema, no han llegado instrucciones completas de Tokio, pero las espera a mediados de este mes.

Él se fue el domingo en la noche para investigar cuestiones laborales japonesas en una colonia de Monterrey, posteriormente hará un interrogatorio informal en la frontera y regresará en dos semanas para recibir instrucciones finales. Entonces estará preparado para ir hacia al norte y colaborar con cualquier oficial estadounidense asignado a reunirse con él y pedirá permiso para continuar en Washington para una conferencia con el embajador japonés.

En ese viaje, notificará sus movimientos al embajador por medio de telégrafo, pero no desea que sean comunicados de manera oficial por el embajador al Departamento (del Estado) porque siente que si la atención fuera dirigida hacia él ahora mismo no podría asegurar la evidencia buscada.

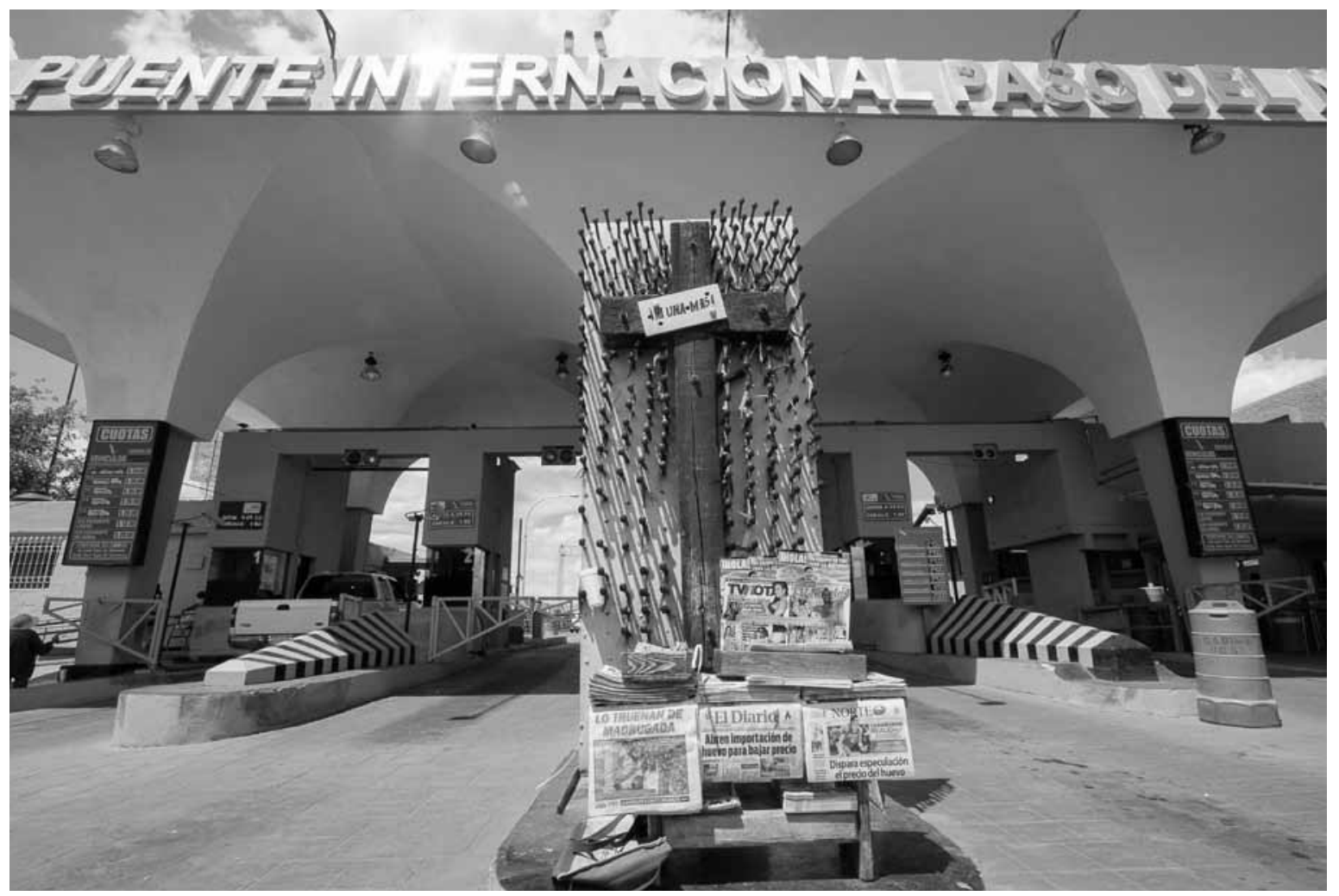

Prometeo Lucero • Frontera Ciudad Juárez-El Paso, 2014 
En cuanto al gobierno mexicano, piensa que no debe tomarse ninguna acción hasta que las irregularidades de las cuales hubo quejas sean establecidas de manera suficiente.

El japonés Nonami, quien fue el agente principal en la promoción de la inmigración ilegal, ha regresado a su país, donde ahora está bajo arresto.

Tengo el honor de ser

David E. Thompson

Departamento de Comercio y Trabajo

Servicio de Inmigración

\section{Documento 10}

Se reportan negociaciones con México sobre el tráfico de japoneses en la frontera

Oficina del Inspector Supervisor

El Paso, Texas

7 de octubre de 1911

Para contestar, refiérase a núm. 5002/129

Comisionado general de Inmigración

Washington, D. C.

Señor:

Referente al tema de las negociaciones con México que buscan restringir la inmigración china (Archivo de la Agencia Número 51463-C) se transmite adjuntado un recorte del El Paso Times, que indica la tendencia del sentimiento popular en el noroeste de México respecto de la inmigración china.

Atentamente,

Firma ilegible

Inspector Supervisor

Anexo 30367

wrc

\section{Documento 11}

Reporte de un agente investigador sobre el tráfico de japoneses en Juárez. Transcripción de varias entrevistas con informantes sobre el tráfico y corrupción en la frontera

En respuesta al archivo número 236/76-77

Departamento del Estado

Washington

Secretaria de Comercio y Trabajo

Señor:

Confirmo la recepción de su carta del 9 de marzo de 1908 relativa al contrabando de trabajadores japoneses y chinos hacia Estados Unidos desde México, adjunto una copia del reporte de inspector de Inmigrantes Charles L. Babcock acerca del tema.

Para su información, adjunto una copia de mi carta del 26 de marzo de 1908 al embajador japonés y documentos.

El reporte del señor Babcock será regresado posteriormente.

Tengo el honor de ser, Señor, su sirviente obediente,

Firma ilegible

Documentos adjuntos para el embajador japonés, núm. 14, 1908

Agencia Japonesa

Calle del Comercio núm. 64

Apartado 46, Ciudad Juárez

Teléfono 3923 Chihuahua, México

Extracto de la entrevista con Nakazo

P. Conoce usted algo. México ¿?

R. Sí.

P. ¿Qué es lo que sabe acerca de ellos?

R. Él, la policía le agarró y le metieron a la cárcel. 


\section{P. ¿De qué crimen le inculparon?}

R. Pusimos una queja con la policía que estaban llevando a cabo este negocio sin una licencia del gobierno y que consideramos que lo estaba robando de los japoneses.

P. ¿Sabe qué disposición se tomó en este caso?

R. Lo metieron a la cárcel por la noche, lo examinaron y le encontraron mil dólares de moneda mexicana y a la mañana siguiente lo dejaron ir, pero no sé si lo multaron o no.

(Nota: Nakazo Nojima, el mencionado anteriormente, es el partidario que organizó la Asociación Benevolente Japonés Americano, cuyo propósito está incluido en la copia del anuncio adjunto a esta exposición.)

\section{Declaración de B. K. Matsunaga \\ De inspector Babcock:}

P: ¿Cuál es su nombre?

R: B. K. Matsunaga.

P: ¿Cuánto tiempo ha estado en Estados Unidos?

R: Llegué a Estados Unidos en 1893.

P: ¿Cuánto tiempo ha vivido en El Paso?

$\mathrm{R}$ : Aproximadamente cuatro años.

P: ¿En qué negocio se desempeñó durante el tiempo que vivió en El Paso?

R: Abrí un restaurante en 505 South El Paso Street, lo dirigí por aproximadamente un año y después abrí una tienda de abarrotes en 302 San Francisco Street, que dirigí por tres años. También estaba interesado en una casa de huéspedes japoneses en Juárez, México. Vendí mi tienda de abarrotes el 13 de julio pasado, dejé El Paso, me fui a San Francisco y hace poco regresé a El Paso.

P: ¿Durante el tiempo que vivió en El Paso llegó a conocer a Nonami y Hasegawa, dos japoneses quienes manejan la Agencia Japonesa en Juárez, México?

R: Sí.
P: ¿Cuál es el objetivo de esta Agencia?

R: El objetivo fue ayudar a japoneses a entrar a Estados Unidos, cobrándoles una cantidad considerable.

P: ¿Alguna vez notó que los oficiales de Inmigración actuaran como si ayudaran a Nonami y Hasegawa en su trabajo?

$\mathrm{R}$ : Me pareció gracioso, cuando abrí la casa de huéspedes, tenía a dos muchachos que querían ir a Canadá y los mandé a la oficina de Inmigración y la Agencia les mandó una docena al mismo tiempo. Los que envió la Agencia pasaron el mismo día. Los que yo mandé estaban en la estación todo el día y toda la noche hasta que los dejaron pasar. Nonami y Hasegawa dijeron que todos los japoneses deben acudir a su Agencia para pasar rápido.

P: ¿Alguna vez escuchó que alguno de nuestros oficiales estaba recibiendo dinero de Nonami y Hasegawa por ayudarles a cruzar a los japoneses? R: No.

P: ¿Cómo, en su opinión, cómo hacían que pasara la mayoría de sus clientes?

R: No sé.

P: ¿Conoce japoneses que tal vez sepan algo sobre esta Agencia, dispuestos a proporcionarme la información para poder terminar este negocio ilícito?

R: No se me ocurre nadie.

P: ¿Conoce al señor Pruett, el intérprete japonés? R: Sí.

P: ¿Alguna vez lo vio en Juárez?

R: Sí, solía ir tres o cuatro veces a la semana y hablar con los japoneses. Él iba a mi tienda con frecuencia. Joe Matsomoto y otros japoneses iban a la casa de Pruett muchas veces por la noche. Alguna vez, creo que en marzo de 1907, Miura, un japonés de Denver, llegó a El Paso y Joe Matsomoto me contó que él y Miura fueron a la casa de Pruett y trajeron una caja de cigarros. Poco después de que Matsomoto me contó eso, 97 japoneses fueron llevados de Juárez a Denver por el ferrocarril de Santa Fe en un coche especial. 


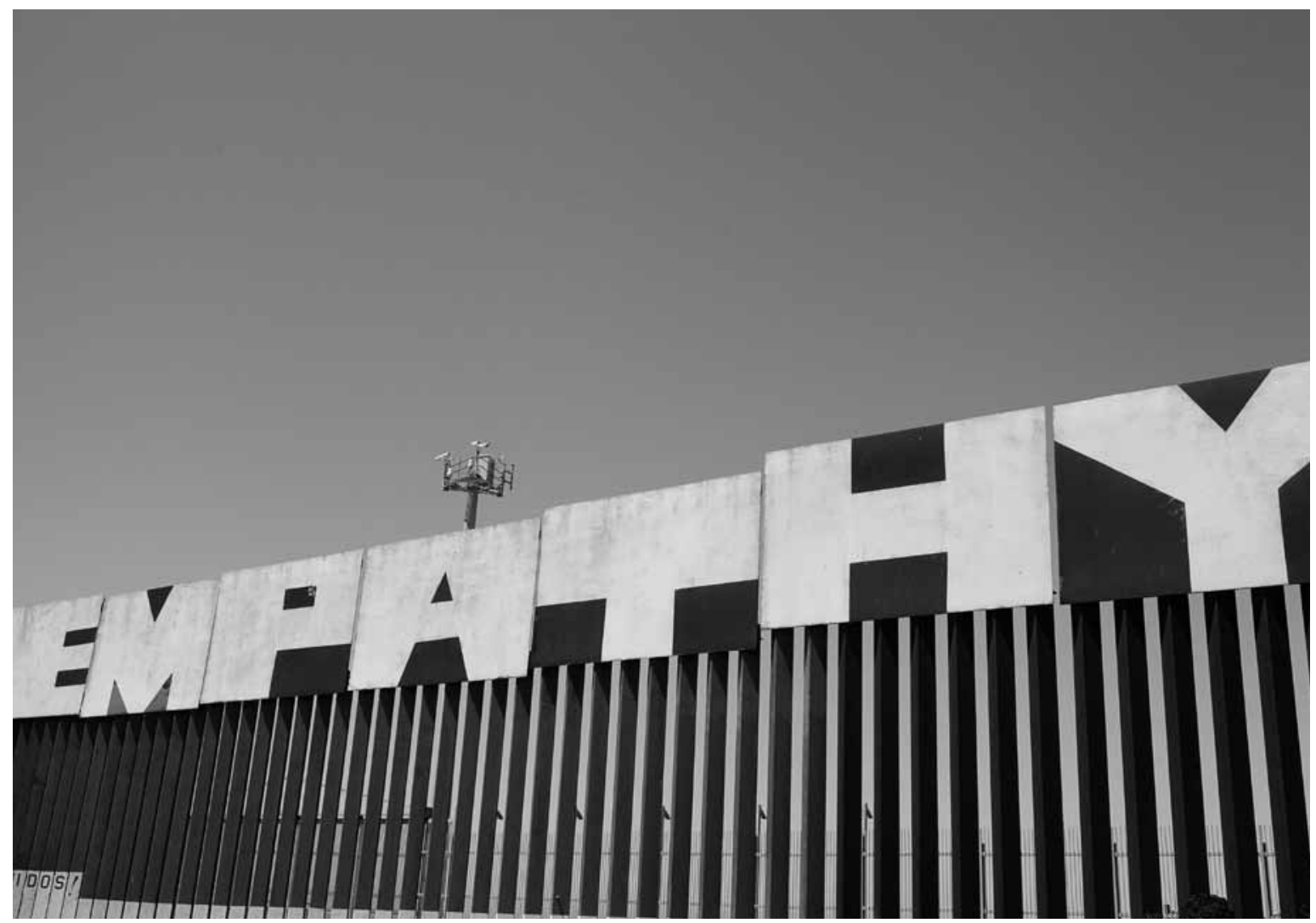

Prometeo Lucero • Muro fronterizo, Tijuana, 2014.

\section{P: ¿Usted va a...? \\ R: Sí.}

Sin embargo, el señor Matsunaga no proporcionó ninguna información relativa a la admisión de los japoneses a El Paso. Referente a su declaración de que 97 japoneses habían sido llevados de Juárez a Denver en ese entonces, no fui capaz de averiguar la fecha exacta, no obstante estoy muy satisfecho porque él se refería a algún movimiento de japoneses en tránsito. Durante ese tiempo muchos japoneses fueron admitidos legamente al pasar a través de Estados Unidos.

Declaración de doctor J. W.

De inspector Babcock:
P: Doctor, ¿usted está relacionado con el Servicio en este punto, verdad?

R: Sí, soy el cirujano en funciones, Ph. y M. H. S. en la Puerta de El Paso.

P: ¿Cuánto tiempo ha permanecido en esta Puerta? R: Un año.

P: ¿Durante el tiempo que ha estado conectado con el Servicio en El Paso, ha notado algunas irregularidades o acciones por parte de los oficiales de Inmigración en conexión con ciertos japoneses u otras personas que en su opinión fueron indiscretas o indecorosas para un oficial del Servicio?

$\mathrm{R}$ : He visto algunas cosas que pensé que eran poco prudentes por parte de los oficiales de Inmigración, como la aceptación de favores de los interesados en la admisión de los inmigrantes. 
P: ¿Podría declarar la naturaleza de estos favores a los que se refiere?

R: Aceptar invitaciones a cenas y otros refrigerios, como cigarros, etcétera, y regalos de todo tipo.

P: ¿A cuál oficial u oficiales se refiere particularmente?

R: Ha sido una conducta general por parte de los oficiales que tienen relación con la oficina, por lo que los extranjeros son admitidos o impedidos a aceptar tales favores.

Declaración del inspector chino Griffin

Del inspector Babcock:

P: Durante el tiempo que ha estado en contacto con este Servicio en El Paso, ha notado algunas irregularidades o acciones por parte de los oficiales de Inmigración, ¿en particular en sus relaciones con los japoneses?

R: Un día en septiembre yo estaba en Juárez para asistir a una corrida de toros y conocí al inspector Dodd y al intérprete Pruett. Les pregunté si irían a la corrida durante su jornada laboral y el señor Pruett dijo que no haría una cosa así. Finalmente, se deshicieron de mí y después los vi en compañía de un japonés, quien compró boletos y le dio uno a cada uno y se fueron a la corrida juntos.

\section{Documento 12}

Traducción de la carta de un japonés en una granja cerca de Los Ángeles, EUA, para su amigo en México

Yo llegué a Ciudad Juárez a las 9 p. m. el 18 de septiembre y me quedé hasta el siguiente día, sólo podía entrar a este país como comerciante gracias a la ayuda del señor Hasegawa y del señor Nonami, ya que el señor Torii había sido autorizado por el inspector de Inmigración, quien le proporcionó su boleto de ferrocarril para Canadá.
Cuando me bajé del tren en Juárez, me encontré con el señor Sugimoto y al siguiente día vi al señor Kichizo Suzuki. Como les faltaba dinero les presté un poco para que cruzaran la frontera.

Salí de El Paso a las 6:20 p. m. el día 19 y llegué a Los Ángeles a las 2:40 p. m. del siguiente día, me quedé esa noche en el Hotel Okita. Al siguiente día fui a la casa del señor Ozawa y pregunté en el Hotel Okita por teléfono sobre mis amigos y ya que me dijeron que estaban ahí fui a verlos y regresé con ellos a la casa del señor Ozawa. La distancia de Los Ángeles a la casa del señor Ozawa son dos [...] y con el señor Alizo son otros dos [...] Llegamos con el señor A. a las 11:00 de esa noche y el día 20 comenzamos a trabajar en una granja piscando uvas. Por juntar uvas se paga bien, podíamos ganar entre $\$ 3.20$ y $\$ 3.30$ oro al día, y por la pisca de fresa $\$ 1.40$ al día. Hay bastante trabajo a dondequiera que vayamos, ven de inmediato.

Te cuesta $\$ 30.15$ (o $\$ 80.15$ mex.) ir de la ciudad de México a Ciudad Juárez que es el pueblo en la frontera, y \$60.00 de El Paso a Los Ángeles para el pasaje de tren, y 50 centavos al día son suficientes para los gastos en el tren. En la frontera debes pagar una comisión de \$20.00 mex. a la Agencia Japonesa, si deseas ir a Canadá, además de $\$ 99.00$ mex. para pasaje y $\$ 8.00$ como impuesto de extranjero; pero si deseas pasar como comerciante yendo a Canadá deberás pagar a la Agencia $\$ 140.00$ mex., $\$ 99.00$ por el pasaje y $\$ 8.00$ como impuesto de extranjero. Si deseas pasar como comerciante a Estados Unidos deberás pagar $\$ 120.00$ a la Agencia y $\$ 8.00$ como impuesto de extranjero y $\$ 60.00$ para el pasaje a Los Ángeles.

Como debes pasar por un examen riguroso en la frontera si quieres entrar como comerciante que va a Estados Unidos (debes llevar ropa de primera clase, no puedes tener callosidad en las manos o no puedes mostrar ninguna señal de ansiedad, etcétera), para ti el mejor plan es obtener el permiso para ir a Canadá y salirte del tren en el camino, pero dicen que en este caso no puedes trabajar en las 
ciudades, en las fábricas o en los ferrocarriles hasta un año después de entrar al país, pero si entras como comerciante puedes trabajar donde quieras y elegir cualquier tipo de trabajo.

El río que divide Ciudad Juárez y El Paso tiene sólo 80 metros de ancho y si pasas aproximadamente 300 metros río arriba puedes cruzar sin ser descubierto, pero no puedes comprar agua ni comida en el camino hasta que llegues a Los Ángeles, es imposible la entrada secreta.

\section{Documento 13}

Testimonio de Kamoto Ota. Testigo jurado.

P: ¿Cuál es su nombre?

R: Kamoto Ota.

P: ¿Dónde vive?

R: En El Paso, Texas, y también en Juárez, México.

P: ¿Cuántos años tiene?

R: Tengo 22 años.

P: ¿Cuándo aplicó para ser admitido a EUA?

R: El 16 de enero de 1906.

P: ¿Fue admitido en ese tiempo por los oficiales de Inmigración de esta Puerta?

R: Sí.

$\mathrm{P}$ : ¿Conoce al intérprete japonés?

R: Sí.

P: ¿Cómo llegó a conocerlo y bajo qué circunstancias?

R: Pues lo conocí aquí en la Agencia de Inmigración cuando apliqué para ser admitido a Estados Unidos.

P: ¿Contó su caso a los oficiales?

R: Sí.

P: ¿Conoce su nombre?

R: Le llaman Ging.

P: ¿Alguna vez el intérprete, el señor Hasegawa, le exigió dinero? Si sí, ¿cuándo y para qué fin?
R: Me pidió cinco dólares y dos dólares para el head tax, en total siete dólares.

P: ¿Para qué, si es que dijo, para qué eran los cinco dólares?

R: Ging dijo "debes pagar dos dólares para el head tax, y pagarme cinco dólares por dejarte entrar a los Estados Unidos".

P: ¿Le dijo Ging que si no le pagaba no lo dejaría entrar a Estados Unidos?

R: Sí.

P: ¿En dónde le pagó ese dinero a Ging?

R: En El Paso.

P: ¿Después de que fue admitido?

R: Sí.

P: ¿Le dijo Ging para qué quería los cinco dólares?

R: Dijo que los cinco dólares fueron para su comisión por haber interpretado ante la Oficina de Inmigración.

P: ¿Está consciente de que Ging distorsionó los hechos cuando le pagó los cinco dólares?

R: Me di cuenta anoche que él robó el dinero.

P: ¿Le pidió que le regresara los cinco dólares?

R: Se los pediré cuando lo vea.

P: ¿Sabe si Ging recibió dinero de otros japoneses que aplicaron para admisión?

R: Sí.

P: ¿Me puede dar los nombres, si los sabe?

R: Uno fue Jayachi Kuwana.

P: ¿Dónde vive?

R: En Juárez.

P: ¿Está aquí actualmente?

R: Sí.

P: ¿Qué hace allá?

R: Ahora no hace nada.

P: ¿Ha sido admitido a los Estados Unidos?

R: No, lo mandaron de regreso.

P: ¿Sabe si Jayachi Kuwana ha pagado dinero a Ging fuera de los dos dólares para el head tax?

R: Sí.

P: ¿Cuánto, si es que sabe?

R: Cerca de 15 dólares en dinero mexicano. 
P: ¿Para qué dijo que iba a usar ese dinero, si sabe? R: Dijo que incluía su cuota para interpretar, el impuesto fijo, y también para la atención médica. También dijo que si este dinero no era pagado, nunca pasaría por El Paso.

P: ¿Es esta declaración absolutamente verdadera según su mejor conocimiento?

R: Sí, señor.

Nota del compilador: en el expediente hay otras entrevistas semejantes, que ponen en evidencia la corrupción del traductor. Dado que son similares se optó por omitirlas.

\section{A modo de conclusión}

Los documentos reseñados ponen en evidencia la añeja particularidad de México como lugar de tránsito hacia Estados Unidos y la relevancia de las ciudades fronterizas donde se desarrollan servicios especializados para el tráfico de personas. Por otra parte, se demuestra de manera fehaciente cómo las leyes de migración de un país, sean generales o específicas para determinados grupos - en este caso chinos y japoneses-, tienen repercusiones múltiples y no involucran sólo a los países de origen y destino, sino a otros, como sucede en el caso de la migración en tránsito por México. Los migrantes de ayer y hoy suelen jugar a tres o más bandas, por utilizar una metáfora del billar, y utilizan cualquier resquicio legal para salir del país de origen y llegar poco a poco, en escalas, a su lugar de destino. Los migrantes cubanos de hoy aprovechan la oportunidad de viajar a Ecuador o Venezuela sin visa, para luego dirigirse hacia el norte, atravesar México y llegar a Estados Unidos, donde tienen asegurado ingreso y asilo político.

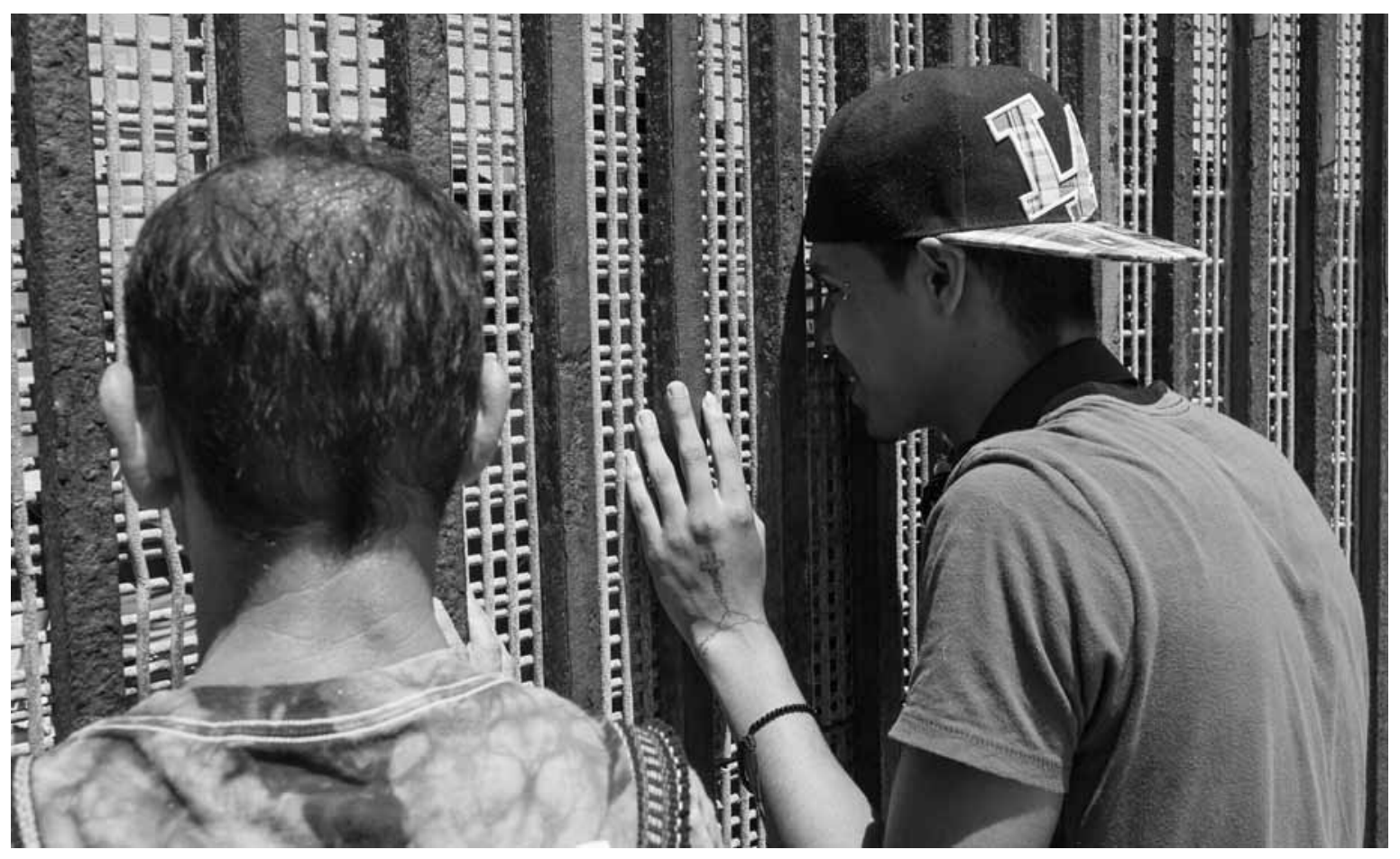

Prometeo Lucero Muro fronterizo, Tijuana, 2014. 
Las leyes migratorias estadounidenses de antaño solían cerrar o abrir sus puertas a determinadas personas por razones raciales, o racistas, para ser más específicos. En la actualidad los motivos raciales se consideran políticamente incorrectos, aunque siempre exista un trasfondo de este tipo disimulado por consideraciones políticas: durante la Guerra Fría se limitaba o dificultaba el ingreso de personas con antecedentes políticos ligados al comunismo, al socialismo o al anarquismo, hoy los argumentos que definen las exclusiones son la guerra contra el narcotráfico y el terrorismo, de acuerdo con nacionalidades de origen, religión o etnia.

No obstante, los migrantes como entes individuales o colectivos siempre encuentran vías alternas para subvertir o superar las barreras burocráticas y formales que se les imponen. Las razones que los países o los gobiernos aducen para incluir o excluir a determinados grupos o personas cambian, evolucionan y se transforman por la fuerza y la determinación de los sujetos migrantes, que con el tiempo se convierten en ciudadanos y alteran los motivos de la exclusión. También cambian los países, como Japón, que fomentaba la salida de sus nacionales a fines del siglo XIX y comienzos del xx y a la vuelta de los años se convierte en país receptor de mano de obra e impone condiciones y requisitos muy severos para el ingreso y prácticamente anula las posibilidades de la permanencia definitiva para los inmigrantes de otro origen étnico. El estudio de la migración en tránsito por México es una tarea pendiente, tanto para historiadores que podrían contar con muchísima documentación al respecto como para antropólogos que quieran hacer trabajo de campo en la ruta migratoria que va del Río Suchiate en la frontera sur al Río Bravo en el norte. D

\section{Bibliografía}

Ota Mishima, María Elena, 1985, Siete migraciones japonesas en México, 1890-1978, El Colegio de México, México.

- 1997, "Características sociales y económicas de los inmigrantes japoneses en México”, en María Elena Ota Mishima (coord.), Destino México. Un estudio de las migraciones asiáticas siglos xix y xx, El Colegio de México, México. 